\title{
Improved 1-Deoxynojirimycin (DNJ) production in mulberry leaves fermented by microorganism
}

\author{
Yun-Gang Jiang ${ }^{1}$, Chu-Yan Wang ${ }^{1,3}$, Chao Jin ${ }^{1}$, Jun-Qiang Jia ${ }^{1,2}$, Xijie Guo ${ }^{1,2}$, \\ Guo-Zheng Zhang ${ }^{1,2}$, Zhong-Zheng Gui ${ }^{1,2}$ \\ ${ }^{1}$ Jiangsu University of Science and Technology, Zhenjiang, China. \\ ${ }^{2}$ Sericultural Research Institute, Chinese Academy of Agricultural Sciences, Zhenjiang, China. \\ ${ }^{3}$ Department of Biological and Environmental Engineering, Hefei University, Hefei, China.
}

Submitted: December 31, 2012; Approved: September 09, 2013.

\begin{abstract}
DNJ, an inhibitor of $\alpha$-glucosidase, is used to suppress the elevation of postprandial hyperglycemia. In this study, we focus on screening an appropriate microorganism for performing fermentation to improve DNJ content in mulberry leaf. Results showed that Ganoderma lucidum was selected from 8 species and shown to be the most effective in improvement of DNJ production from mulberry leaves through fermentation. Based on single factor and three factor influence level tests by following the Plackett-Burman design, the optimum extraction yield was analyzed by response surface methodology (RSM). The extracted DNJ was determined by reverse-phase high performance liquid chromatograph equipped with fluorescence detector (HPLC-FD). The results of RSM showed that the optimal condition for mulberry fermentation was defined as $\mathrm{pH}$ 6.97, potassium nitrate content $0.81 \%$ and inoculums volume $2 \mathrm{~mL}$. The extraction efficiency reached to $0.548 \%$ in maximum which is 2.74 fold of those in mulberry leaf.
\end{abstract}

Key words: mulberry, DNJ Production, microorganisms, fermentation.

\section{Introduction}

Mulberry (Morus alba L.) has traditionally been cultivated in China, Japan, Korea, India, Brazil etc to use its leaves for feeding silkworms (Bombyx mori L.) or as Chinese herbal tea based on folklore. Mulberry has long been documented in various scientific studies, exploring its medicinal worth (Butt et al., 2008). The root bark of mulberry trees has been used for anti-inflammatory, diuretic, antitussive, and antipyretic purposes in oriental medicine, whereas mulberry fruits are used as a tonic and sedative. Mulberry leaves as protein source in food formulations and neuroprotective functions can be used against neurodegenerative disorders such as Alzheimer and Parkinsonism (Niidome et al., 2007), and can also be considered for special use to improve skin tone (Lee et al., 2002; Fang et al., 2005). Nowadays, importance of natural products is being revitalized to alleviate various health discrepancies. The link between health and diet is well documented and the consumers' trend reflects conscience towards their dietary habits. Mulberry leaves have been known to be rich in 1-deoxynojirimycin (DNJ) which inhibits postprandial hyperglycemia by inhibiting $\alpha$-glucosidase in the small intestine (Asano et al., 2001; Gui et al., 2001), has anti-virus (Durantel et al., 2001; Lazar et al., 2007) and anti-tumor (Lou et al., 2010) activities, and modestly decreases serum triglyceride (TG) level in humans (Kojima et al., 2010). Presently, various food grade mulberry (such as teas, powders, and tablets) have been made commercially available in China, Japan, Korea and other countries (Asano et al., 2001; Gui et al., 2004).

DNJ has been isolated from natural source. It was first isolated from the root bark of a Morus (mulberry) species (Yagi et al., 1976) and also produced by various microorganisms, including species from Streptomyces (Gui et al., 2004) and Actinoplanes (Schmidt et al., 1977), Flavobacterium saccharophilium (Kameda et al., 1980) and Bacillus subtilis (Stein et al., 1984). Due to microorganism's fast-growing characteristic, there has been increased interest in identifying DNJ from broth of certain microorgan- 
isms (Zheng et al., 2006). To obtain industrial-scale production of DNJ and its derivatives, several reports have been published dealing with study of the fermentation by Actinoplanes spp. SE-50 (Schmidt et al., 1977), Bacillus subtilis B2 from okara (soy pulp) (Zhu et al., 2010), and Streptomyces lavendulae (Chalunton et al., 2009; Kojima et al., 1995). Except for selecting the appropriate strain, fermentation conditions played a significant role in final productivity of secondary metabolites. When the fermentation was performed, maintaining the dissolved oxygen at $20 \%$ and $\mathrm{pH}$ at less than 7 helped the production reach its peak value (Kojima et al., 1995). Nevertheless, DNJ content in mulberry leaf is about $0.1 \%$ (Kimura et al., 2007), which may be too low to show an effect. Furthermore, there are several limitations in large-scale DNJ production. (Chalunton et al., 2009; Wei et al., 2011). Thus, there is much interest in identifying a suitable microorganism to carry out fermentation of mulberry leaf to improve the production of DNJ in industrial scale.

There are several statistical techniques, such as response surface methodology (RSM) (Jiang et al., 2010), artificial neural network (ANN) and genetic algorithm (GA) (Sathish and Prakasham, 2010), which have been developed based on human decision-making processes and unorthodox search for determining the optimal settings for experimental factors that give the maximum (or minimum) value for response. RSM is a useful statistical tool for its potential use in biotechnological fields. It has brought benefits to the extent that an industrial process has been proposed for manufacturing nutraceutical products.

In a previous study, we have carried out the optimal extraction condition for DNJ from mulberry broth extraction with diluted acid $(0.05 \mathrm{M} \mathrm{HCl})$. We defined three factors namely temperature, extraction time and the ratio of solid to liquid followed by response surface methodology (RSM) to gain the optimum extraction yield. Considering low content of plant- and micro-derived products, screening an advantageous strain and optimization of fermentation conditions for mulberry were investigated in this study.

\section{Materials and Methods}

\section{Mulberry leaf}

Mulberry leaves were collected from the plantation of mulberry (Sericultural Research Institute, Chinese Academy of Agricultural Sciences, Zhenjiang, China). The leaf was ground to powder for fermentation. To understand the DNJ distribution in different part leaves from mulberry branch, the shoots, young leaves and mature leaves have been harvested and determined.

\section{Microorganism and culture}

Eight species of microorganism, Candida tropicalis, Ganoderma lucidum, Cordyceps sinensis (Berk.) Sacc, Phellinus igniarius (L.ex Fr.) Quel, Ganoderma applanatum (Pers. Ex Wallr) Pat, Schizophyllum commune Franch, Cordyceps militaris and Antrodia camphorate, were selected and isolated from a heterogenous population of organism. All the species were maintained on a potato dextrose agar (PDA) slant consisting of potato $(2 \mathrm{~g} / \mathrm{L})$, glucoses $(0.2 \mathrm{~g} / \mathrm{L})$, agar $(0.25 \mathrm{~g} / \mathrm{L})$ and vitamin $\mathrm{B}_{1}$ $\left(5 \times 10^{-4} \mathrm{~g} / \mathrm{L}\right)$ at $4{ }^{\circ} \mathrm{C}$.

The species of Candida tropicalis was inoculated in a $250 \mathrm{~mL}$ shake flask containing $100 \mathrm{~mL}$ of a seed medium $(\mathrm{pH} 6.0)$ consisting of glucose $(0.6 \mathrm{~g} / \mathrm{L})$, tryptone $(0.05 \mathrm{~g} / \mathrm{L})$, yeast extract $(0.03 \mathrm{~g} / \mathrm{L})$, calcium chloride $(2.5 \mathrm{x}$ $\left.10^{-3} \mathrm{~g} / \mathrm{L}\right)$, magnesium sulfate $\left(2.5 \times 10^{-3} \mathrm{~g} / \mathrm{L}\right)$ and monopotassium phosphate $\left(2.5 \times 10^{-2} \mathrm{~g} / \mathrm{L}\right)$. The others were grown on improved PDA media containing glucose $(0.2 \mathrm{~g} / \mathrm{L})$, tryptone $(0.02 \mathrm{~g} / \mathrm{L})$, magnesium sulfate $\left(5 \times 10^{-3} \mathrm{~g} / \mathrm{L}\right)$, calcium chloride $\left(1 \times 10^{-3} \mathrm{~g} / \mathrm{L}\right)$ and monopotassium phosphate $\left(5 \times 10^{-3} \mathrm{~g} / \mathrm{L}\right)$ at $28^{\circ} \mathrm{C}$ for 7 days to guarantee that the seeds were totally active.

Eight candidate species of microorganism were selected for fermentation of mulberry leaf powder. One $\mathrm{mL}$ broth containing $0.5 \mathrm{~g}$ mulberry leaf powder, $0.6 \%$ potassium nitrate at $\mathrm{pH} 6.5$ and $1 \mathrm{~mL}$ of inoculum strain was fermented at standard condition.

\section{Determination of viable count}

In order to keep control of appropriate population and make sure in the active state of Fungus, the determination of viable count should be performed before inoculation. The agar-plate method was applied using sterile distilled water containing $0.9 \%$ sodium chloride for successive dilutions of the fermentation broth with PDA as plating medium. The visible colonies were counted in $8 \mathrm{~h}$ incubating at $28^{\circ} \mathrm{C}$, approximately $10^{9}$ colony forming units (cfu) $/ \mathrm{mL}$ after $16 \mathrm{~h}$ at the stationary phase.

\section{Optimization of fermentation conditions}

A three-step procedure was performed to optimize the fermentation indices involving (1) Plackett-Burman (PB) design for screening the 3 major influence factors that obviously affect the variation of DNJ production, (2) Single Factor assays to find out the efficacious extent of each factor that significantly improve the production of DNJ, and (3) Box-Behnken design optimizing the best conditions for fermentation with response surface methodology (RSM). PB design involved a set of 12 experiments in -1 and +1 levels $(+1$ level was 1.25 times the value of -1 level). In addition, there were three virtual variables $\left(X_{9}, X_{10}\right.$ and $X_{11}$, data not shown in Table 1) to obtain the estimate of standard error. Based on the results of PB design, each one in 3 major effective factors was selected cover a wide range to ascertain the tendency of DNJ variation.

\section{Derivatization}

DNJ extraction and derivatization was carried out according to the procedure described by Jiang et al. (2010). Briefly, the broth powder was added to $0.05 \mathrm{M} \mathrm{HCl}$ (1:282, $\mathrm{w} / \mathrm{v}$ ), taking a warm bath for $3 \mathrm{~h}$ and $18 \mathrm{~min}$ at $72.9^{\circ} \mathrm{C}$, and 
Table 1 - The analysis of Plackett-Burman design in twelve parallel assays.

\begin{tabular}{llcccc}
\hline Source & Factor & -1 & +1 & Probability of T-test absolute value & Order \\
\hline$X_{4}$ & Fermentation time / day & 2 & 2.5 & 0.066279 & 5 \\
$X_{5}$ & Content of carbon source / $\%$ & 1 & 1.25 & 0.096601 & 8 \\
$X_{3}$ & Inoculation volume / $\mathrm{mL}$ & 1 & 1.25 & 0.062750 & 3 \\
$X_{6}$ & Ratio of material to solution & 5 & 6.25 & 0.093976 & 7 \\
$X_{7}$ & Fermentation Temperature $/{ }^{\circ} \mathrm{C}$ & 25 & 31.25 & 0.064036 & 4 \\
$X_{1}$ & Range of pH value & 6.4 & 8.0 & 0.043727 & 2 \\
$X_{2}$ & Content of nitrogen source / $\%$ & 0.61 & 0.76 & 0.048903 & 2 \\
$X_{8}$ & Rotation per minute of flask & 144 & & & \\
\hline
\end{tabular}

centrifuged at $10785 \mathrm{~g}$ for $10 \mathrm{~min}$. The supernatant was vacuum-filtered and diluted to $200 \mathrm{~mL}$ with water (coordinated to $\mathrm{pH}$ 8.0). The diluted extract was utilized for further derivatization. Ten milliliters of DNJ standard solution or mulberry extract was mixed with $10 \mu \mathrm{L}$ of $0.4 \mathrm{M}$ potassium borate buffer $(\mathrm{pH} 8.5)$ in a $1.5 \mathrm{~mL}$ microtube. Twenty microliters of $5 \mathrm{mmol} / \mathrm{L}$ 9-fluorenylmethyl chloroformate (FMOC-Cl) in $\mathrm{CH}_{3} \mathrm{CN}$ was added with immediate mixing and allowed to react at $20{ }^{\circ} \mathrm{C}$ for $20 \mathrm{~min}$ in a water circulator. After that, $10 \mu \mathrm{L}$ of $0.1 \mathrm{M}$ glycine was added to stop the reaction by quenching the remaining FMOC-Cl. The mixture was diluted with $950 \mu \mathrm{L}$ of $0.1 \%$ (v/v) aqueous acetic acid $(17.5 \mathrm{mmol} / \mathrm{L})$ to stabilize the DNJ-FMOC, and filtered through a $0.45 \mu \mathrm{m}$ syringe filter.

\section{Determination of mulberry DNJ}

Mulberry DNJ was determined using HPLC-RD system. This system consists of a liquid chromatograph (Shimadzu, Japan), an LC-10AxL fluorescence detector (excitation $254 \mathrm{~nm}$, emission $322 \mathrm{~nm}$ ), an LC-20 AD gradient pump, an SIL-20A HT automatic sampler, a CTO-20A thermotank (incubator), a Diamonsil C-18 column (250 x $4.60 \mathrm{~mm}, 5 \mu \mathrm{m}$ ) and LC-solution chromatography data processing software. The mobile phase consisted of acetonitrile and $0.1 \%$ of aqueous acetic acid $(45: 55, \mathrm{v} / \mathrm{v})$. The flow rate was adjusted to $1.2 \mathrm{~mL} / \mathrm{min}$, and the column temperature was set at $40^{\circ} \mathrm{C}$. The $\mathrm{DNJ}$ concentration in sample was calculated using the equation of the standard curve. All assays were run in triplicate.

\section{Data analysis}

The model and formula were performed by RSM. The values were calculated as the mean of individual experiments in triplicate. The statistical significance was analyzed by Student's $t$ test and regression analysis and the data were fitted by using the Expert Design 7.1.3 for Windows software (SPSS Inc., USA).

\section{Results}

\section{Determination of DNJ in Morus alba using HPLC-RD}

Typical HPLC-RD chromatograms of DNJ extracted from mulberry leaves were conducted (Figure 1). The correlation between DNJ dose and response is best described by the following equation: injected amount $=$ (area units + $68.00) / 812.51, r^{2}=0.9997$. The result showed that there existed a good linear relationship between DNJ concentrations of $0.5-10 \mathrm{ng} / \mathrm{mL}$ and the area response.

\section{Selection of potential factors}

PB design was a sort of experimental methodology in two levels, which tried making use of least assays to obtain potential factors affecting mostly with a precise estimate from numbers of elements. The results showed that three factors $\left(X_{1}, X_{2}\right.$ and $\left.X_{3}\right)$ affected the extraction efficiency according to the probability of $t$-test absolute value, while others were of distinctive characters (Table 1). It has been implied that carbon and nitrogen sources would play an important role in synthesis of $\alpha$-glucosidase inhibitor in that they may affect the synthesis of DNJ related enzymes (Sathish and Prakasham, 2010). In this study, nitrogen source significantly functioned in contrast to the impact of carbon source.

\section{Appropriate microorganism screening}

Eight candidate species of microorganism were selected for fermentation of mulberry leaf powder. One $\mathrm{mL}$ broth containing $0.5 \mathrm{~g}$ mulberry leaf powder, $0.6 \%$ potassium nitrate at $\mathrm{pH} 6.5$ and $1 \mathrm{~mL}$ of inoculum strain was fermented at standard condition. After fermentation, the broth was dried by hot-air and ground to powder for future determination. The production of DNJ was increased significantly after being fermented by Ganoderma lucidum, Phellinus igniarius (L.ex Fr.) Quel, Cordyceps militaris and Antrodia camphorata. Among them, Ganoderma lucidum was more effective to improve the DNJ yield which reached $0.548 \%$ (5.48 mg/g dry weight of mulberry leaf) after fermentation. It was over 2.5 -fold to mulberry 
A

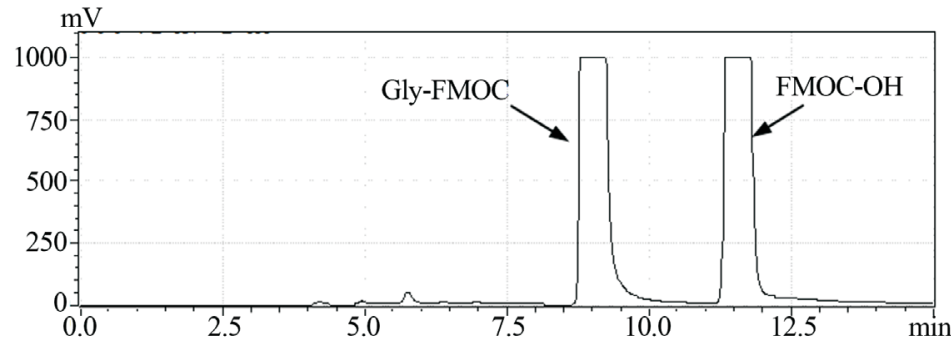

B

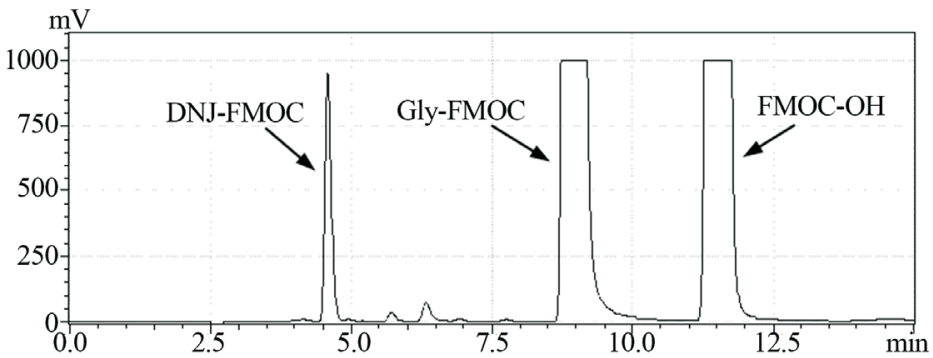

C

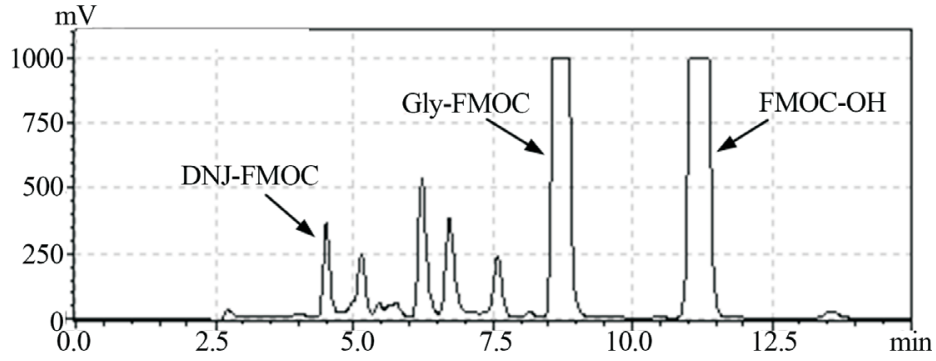

Figure 1 - HPLC-RD analysis of the derivatized 1-deoxynojirimycin (DNJ). (1a) HPLC-RD chromatogram of blank. (1b) HPLC-RD chromatogram of standard DNJ. (1c) HPLC-RD chromatogram of mulberry DNJ. The retention time of three typical peaks (DNJ-FMOC, Gly-FMOC and FMOC-OH) was discrepancy appreciably.

leaves (about $0.2 \%$ ). The DNJ production in mulberry leaves fermented by Phellinus igniarius (L.ex Fr.) Quel, Antrodia camphorata and Cordyceps militaris was $0.359 \%, 0.356 \%$, and $0.337 \%$, respectively (Figure 2). Consequently, the strain of Ganoderma lucidum was selected for the following study of optimal fermentation conditions.

\section{Optimization of fermentation conditions}

Based on the previous study, certain extents of functional factors were performed to confirm the influencing internal tendency. From Table 1, we first conducted single factor tests of the $\mathrm{pH}$ value as $\mathrm{X}_{1}(6.0,6.5,7.0,7.5$ and 8.0$)$, potassium nitrate content as $\mathrm{X}_{2}(0.4,0.6,0.8,1.0$ and $1.5 \%)$, and inoculum volume as $\mathrm{X}_{3}(0.5,1.0,1.5,2.0$ and $2.5 \mathrm{~mL})$

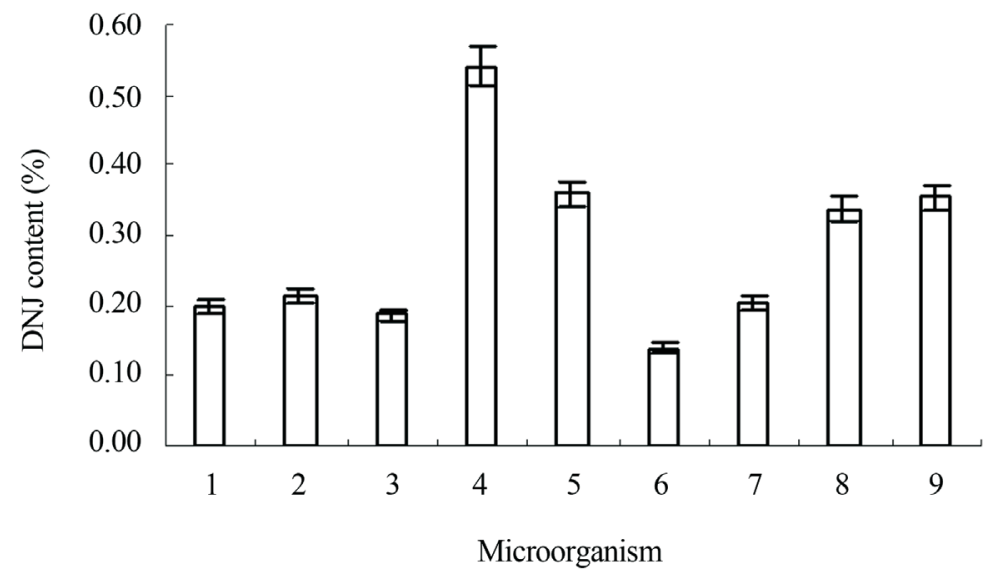

Figure 2 - DNJ production from mulberry leave fermented by different peculiar species. 1 Control, 2 Candida tropicalis, 3 Cordyceps sinensis (Berk.) Sacc, 4 Ganoderma lucidu, 5 Phellinus igniarius (L.ex Fr.) Quel, 6 Ganoderma applanatum (Pers. Ex Wallr) Pat, 7 Schizophyllum commune Franch, 8 Cordyceps militaris, 9 Antrodia camphorata. 
to extraction rate $y(\%)$ (Table 2). The highest amount of extraction rate $(0.3157 \%)$ was obtained when $X_{1}, X_{2}$, and $X_{3}$ were set at $\mathrm{pH} 6.5$, potassium nitrate $0.8 \%$ and inoculum volume $1.0 \mathrm{~mL}$ of Ganoderma lucidum. Next, orthogonal design and response value were observed. The extraction efficiency (DNJ yield, Y) was optimized by RSM, taking up 15 sets of assays (Table 3 ). The results for the regression coefficients of $\mathrm{Y}$ enabled fitting model, consisting of the linear and quadratic terms for $X_{1}$ (pH value), $X_{2}$ (potassium nitrate content) and $X_{3}$ (inoculum volume), to be expressed by the following equation:

$Y=0.0548-9.37 \times 10^{-4} X_{1}+1.25 \times 10^{-5} X_{2}+5 \times 10^{-5} X_{3}-$ $9.75 \times 10^{-4} X_{1} X_{2}+1.50 \times 10^{-4} X_{1} X_{3}+6.5 \times 10^{-4} X_{2} X_{3}-$ $7.32 \times 10^{-3} X_{1}^{2}-9.27 \times 10^{-3} X_{2}^{2}-7.25 \times 10^{-3} X_{3}^{2}$

The actual response value (DNJ yield from incubation broth) was closed to the predicted one (Table 3), suggesting that the regression model for the design was available. The model "Prob $>$ F" value was less than 0.05 (Table 4 ), only $0.18 \%$ does not apply which due to noise interference, indicating the model test is remarkable. The significance of Lack of fit was extremely not obvious so as to ignore it. Model calibration coefficient $R_{A d j}^{2}=0.8813$ shows that the model can explain the change in $88.13 \%$ response value, and only about $12 \%$ of the total variance does not explain with this model. Adeq precision in 9.593 indicates this model is good with fitting degree and small errors in test. Results suggesting that this model can be used to navigate the design space. $X_{1}^{2}, X_{2}^{2}$ and $X_{3}^{2}$ are significant model terms in Table 5 . The results suggest that the most

Table 2 - Single factor assays and determination index (extraction rate, $y$ ) with different combination of the range of $\mathrm{pH}$ value $\left(X_{1}\right)$, content of potassium nitrate $\left(X_{2}\right)$ and the inoculum volume $\left(X_{3}\right)$.

\begin{tabular}{lcccc}
\hline Order & \multicolumn{3}{c}{ Factor value } & $\begin{array}{c}\text { Extraction } \\
\text { rate }(\mathrm{y}, \%)\end{array}$ \\
\cline { 2 - 3 } & $X_{1}$ & $X_{2}(\%)$ & $X_{3}(\mathrm{~mL})$ & \\
\hline 1 & $6.0(-2)$ & $0.6(-1)$ & $1.0(-1)$ & 0.1672 \\
2 & $6.5(-1)$ & $0.6(-1)$ & $1.0(-1)$ & 0.1653 \\
3 & $7.0(0)$ & $0.6(-1)$ & $1.0(-1)$ & 0.1916 \\
4 & $7.5(1)$ & $0.6(-1)$ & $1.0(-1)$ & 0.0949 \\
5 & $8.0(2)$ & $0.6(-1)$ & $1.0(-1)$ & 0.0988 \\
6 & $6.5(-1)$ & $0.4(-2)$ & $1.0(-1)$ & 0.0724 \\
7 & $6.5(-1)$ & $0.6(-1)$ & $1.0(-1)$ & 0.2579 \\
8 & $6.5(-1)$ & $0.8(0)$ & $1.0(-1)$ & 0.3157 \\
9 & $6.5(-1)$ & $1.0(1)$ & $1.0(-1)$ & 0.2016 \\
10 & $6.5(-1)$ & $1.5(2)$ & $1.0(-1)$ & 0.1067 \\
11 & $6.5(-1)$ & $0.6(-1)$ & $0.5(-2)$ & 0.1178 \\
12 & $6.5(-1)$ & $0.6(-1)$ & $1.0(-1)$ & 0.1249 \\
13 & $6.5(-1)$ & $0.6(-1)$ & $1.5(0)$ & 0.1334 \\
14 & $6.5(-1)$ & $0.6(-1)$ & $2.0(1)$ & 0.2088 \\
15 & $6.5(-1)$ & $0.6(-1)$ & $2.5(2)$ & 0.1134 \\
\hline
\end{tabular}

important independent indices were the range of $\mathrm{pH}$ value $\left(X_{1}\right)$, content of potassium nitrate $\left(X_{2}\right)$ and the inoculum size $\left(X_{3}\right)$ in order (Table 6).

The response surface graph depicted by the two out of three factors formed a series of approximate circles with one centre regardless of diverse gradients, simultaneously vaults hanging down took shape at the three-dimensional chart and reach to a maximum. The highest amount of DNJ $(0.548 \%)$ from the fermentation broth by Ganoderma lucidum would be calculated by first order local deviation with equivalence to zero, when $X_{1}, X_{2}$ and $X_{3}$ were set to $6.97,0.81 \%$ and $2 \mathrm{~mL}$, respectively (Figure 3 ).

\section{DNJ production of mulberry leaves fermented by Ganoderma lucidum}

Based on the optimum conditions, mulberry leaves should be involved in the fermentation assays to confirm the consequence. The DNJ content located in different parts from mulberry were $0.333 \%, 0.172 \%$ and $0.062 \%$ (Figure 4). Through fermentation by Ganoderma lucidum, the highest DNJ production was found at young leaves, reached to $0.402 \%, 1.2$-fold of the onset content.

\section{Discussion}

Due to lack of any chromophore and auxochrome in DNJ structure, a rapid and reliable method for 1-deoxynojirimycin (DNJ) has been developed recently followed

Table 3 - Box-Behnken design and observed response value (extraction yield, $\mathrm{Y}$ ), including actual and predicted code, with different combination of the range of $\mathrm{pH}$ value $\left(\mathrm{X}_{1}\right)$, content of potassium nitrate $\left(\mathrm{X}_{2}\right)$ and the inoculum volume $\left(\mathrm{X}_{3}\right)$.

\begin{tabular}{|c|c|c|c|c|c|}
\hline \multirow{2}{*}{$\begin{array}{l}\text { Run } \\
\text { order }\end{array}$} & \multicolumn{3}{|c|}{ Factor value } & \multicolumn{2}{|c|}{ DNJ content $(\%)$} \\
\hline & $X_{1}$ & $X_{2}(\%)$ & $X_{3}(\mathrm{~mL})$ & $\begin{array}{c}\text { Actual } \\
\text { value }\end{array}$ & $\begin{array}{c}\text { Predicted } \\
\text { value }\end{array}$ \\
\hline 1 & $6.5(-1)$ & $0.8(0)$ & $1.5(-1)$ & 0.301 & 0.28 \\
\hline 2 & $7.5(1)$ & $0.8(0)$ & $1.5(-1)$ & 0.219 & 0.24 \\
\hline 3 & $7.0(0)$ & $0.6(-1)$ & $1.5(-1)$ & 0.203 & 0.22 \\
\hline 4 & $6.5(-1)$ & $0.8(0)$ & $2.5(1)$ & 0.288 & 0.28 \\
\hline 5 & $7.0(0)$ & $1.0(1)$ & $2.5(1)$ & 0.256 & 0.24 \\
\hline 6 & $7.0(0)$ & $1.0(1)$ & $1.5(-1)$ & 0.212 & 0.20 \\
\hline 7 & $7.0(0)$ & $0.6(-1)$ & $2.5(1)$ & 0.195 & 0.20 \\
\hline 8 & $7.0(0)$ & $0.8(0)$ & $2.0(0)$ & 0.505 & 0.54 \\
\hline 9 & $6.5(-1)$ & $1.0(1)$ & $2.0(0)$ & 0.214 & 0.26 \\
\hline 10 & $6.5(-1)$ & $0.6(-1)$ & $2.0(0)$ & 0.208 & 0.22 \\
\hline 11 & $7.0(0)$ & $0.8(0)$ & $2.0(0)$ & 0.544 & 0.54 \\
\hline 12 & $7.5(1)$ & $0.8(0)$ & $2.5(1)$ & 0.210 & 0.24 \\
\hline 13 & $7.5(1)$ & $0.6(-1)$ & $2.0(0)$ & 0.243 & 0.22 \\
\hline 14 & $7.5(1)$ & $1.0(1)$ & $2.0(0)$ & 0.189 & 0.18 \\
\hline 15 & $7.0(0)$ & $0.8(0)$ & $2.0(0)$ & 0.595 & 0.54 \\
\hline
\end{tabular}

Numbers in parentheses were coded symbols for levels of independent parameters. 
Table 4 - Variance analysis of regression model.

\begin{tabular}{lllllll}
\hline Source & Sum of squares & df & Mean square & F-value & p-value & Significance \\
\hline Model & $6.29 \times 10^{-4}$ & 9 & $6.99 \times 10^{-5}$ & 12.54 & 0.0062 & $* *$ \\
Lack of fit & $1.77 \times 10^{-5}$ & 3 & $5.90 \times 10^{-6}$ & 1.16 & 0.49 & - \\
Pure error & $1.02 \times 10^{-5}$ & 2 & $5.08 \times 10^{-6}$ & - & - & - \\
Cor total & $6.57 \times 10^{-4}$ & 14 & - & - & - & - \\
\hline
\end{tabular}

**Values of "Prob $>$ F" less than 0.05 indicate model terms are significant.

Table 5 - Table 5. Variance relatives analysis.

\begin{tabular}{lccc}
\hline Std. dev & $2.36 \times 10^{-3}$ & R-Squared & 0.9576 \\
mean & 0.015 & Adj R-Squared & 0.8813 \\
C.V.\% & 16.11 & Pred R-Squared & 0.5342 \\
PRESS & $3.06 \times 10^{-4}$ & Adeq precision & 9.593 \\
\hline
\end{tabular}

by derivatization with $\mathrm{FMOC}-\mathrm{Cl}$, and analyzed by reversed-phase high-performance liquid chromatography (RP-HPLC) equipped with a fluorescence detector (Kim et al., 2003). The isolation of DNJ from other components and stable retention time of peaks appeared to be available for DNJ analysis with HPLC-FD. Even though DNJ was not confirmed by mass spectra during the detection, the final results could be ascertained in accordance with retention time tested just by HPLC repeatedly.

In this study, eight candidate species of microorganism were selected for fermentation mulberry. Results showed that not all species were considered to be efficient to improve mulberry DNJ production followed by fermentation. It is mentioned that fungus of Ganoderma lucidum shows the strongest potential for inoculation in the mulberry fermentation broth, leading to the improvement of DNJ content, whereas there is no pioneering report indicating DNJ in this strain previously. It is therefore likely that DNJ is metabolized by synthetase system of Ganoderma lucidum using the intermediates in mulberry, such as noji- rimycin (NJ), mannojirimycin (MJ) or other DNJassociated molecules.

The optimum conditions, range of $\mathrm{pH}$ value $\left(X_{I}\right)$, content of potassium nitrate $\left(X_{2}\right)$ and the inoculum volume $\left(X_{3}\right)$, designed by Box-Behnken and assayed with RSM were found to be significant for fermentation of mulberry to improve DNJ production (Table 2). Indeed, fermented under the optimum combination condition regardless of other factors influenced slightly, the DNJ yield reached to a maximum deduced by model, up to $0.548 \%$ (Table 5), whereas mulberry leaf DNJ content was as low as $0.2 \%$. Maintaining $\mathrm{pH}$ at less than 7.0 and dissolved oxygen at $20 \%$ saturation are an important condition in large-scale production of DNJ fermented by Streptomyces lavendulae (Kojima et al., 1995). In this study, $\mathrm{pH}$ at 6.97 for the fermentation by Ganoderma lucidum led to high productivity similar to that of Streptomyces lavendulae, implying that the DNJ synthetase may exhibit the most effective activity in such condition. However, rotation speed of flask, that is to say, dissolved oxygen, had nothing to do with promoting the extract efficiency in Ganoderma lucidum fermentation for mulberry DNJ production. It was apparent that content of trehalose increased along with fermentation temperature fermented by Saccharomyces Cerevisiae KF-7 in repeated-batch scale (Zhong et al., 1995). In our study, the DNJ yield from fermentation broth did not change significantly with temperatures, indicating that temperature does

Table 6 - Verifying difference significance of coefficients in regression formula.

\begin{tabular}{|c|c|c|c|c|c|c|}
\hline Factor & Coefficient estimate & df & Standard error & F-value & p-value & Significance \\
\hline intercept & 0.027 & 1 & $1.36 \times 10^{-3}$ & - & - & - \\
\hline$X_{1}$ & $-9.37 \times 10^{-4}$ & 1 & $8.35 \times 10^{-4}$ & 1.26 & 0.3124 & - \\
\hline$X_{2}$ & $1.25 \times 10^{-5}$ & 1 & $8.35 \times 10^{-4}$ & $2.24 \times 10^{-4}$ & 0.9886 & - \\
\hline$X_{3}$ & $5 \times 10^{-5}$ & 1 & $8.35 \times 10^{-4}$ & $3.59 \times 10^{-3}$ & 0.9546 & - \\
\hline$X_{1} X_{2}$ & $-9.75 \times 10^{-4}$ & 1 & $1.18 \times 10^{-3}$ & 0.68 & 0.4464 & - \\
\hline$X_{1} X_{3}$ & $1.50 \times 10^{-4}$ & 1 & $1.18 \times 10^{-3}$ & 0.016 & 0.9038 & - \\
\hline$X_{2} X_{3}$ & $6.5 \times 10^{-4}$ & 1 & $1.18 \times 10^{-3}$ & 0.30 & 0.6056 & - \\
\hline$X_{1}^{2}$ & $-7.32 \times 10^{-3}$ & 1 & $1.23 \times 10^{-3}$ & 35.50 & 0.0019 & $* * *$ \\
\hline$X_{2}^{2}$ & $-9.27 \times 10^{-3}$ & 1 & $1.23 \times 10^{-3}$ & 56.94 & 0.0006 & $* * *$ \\
\hline$X_{3}^{2}$ & $-7.25 \times 10^{-3}$ & 1 & $1.23 \times 10^{-3}$ & 34.78 & 0.0020 & $* * *$ \\
\hline
\end{tabular}

*** Values of "Prob > F" less than 0.05 indicates model terms significant. 

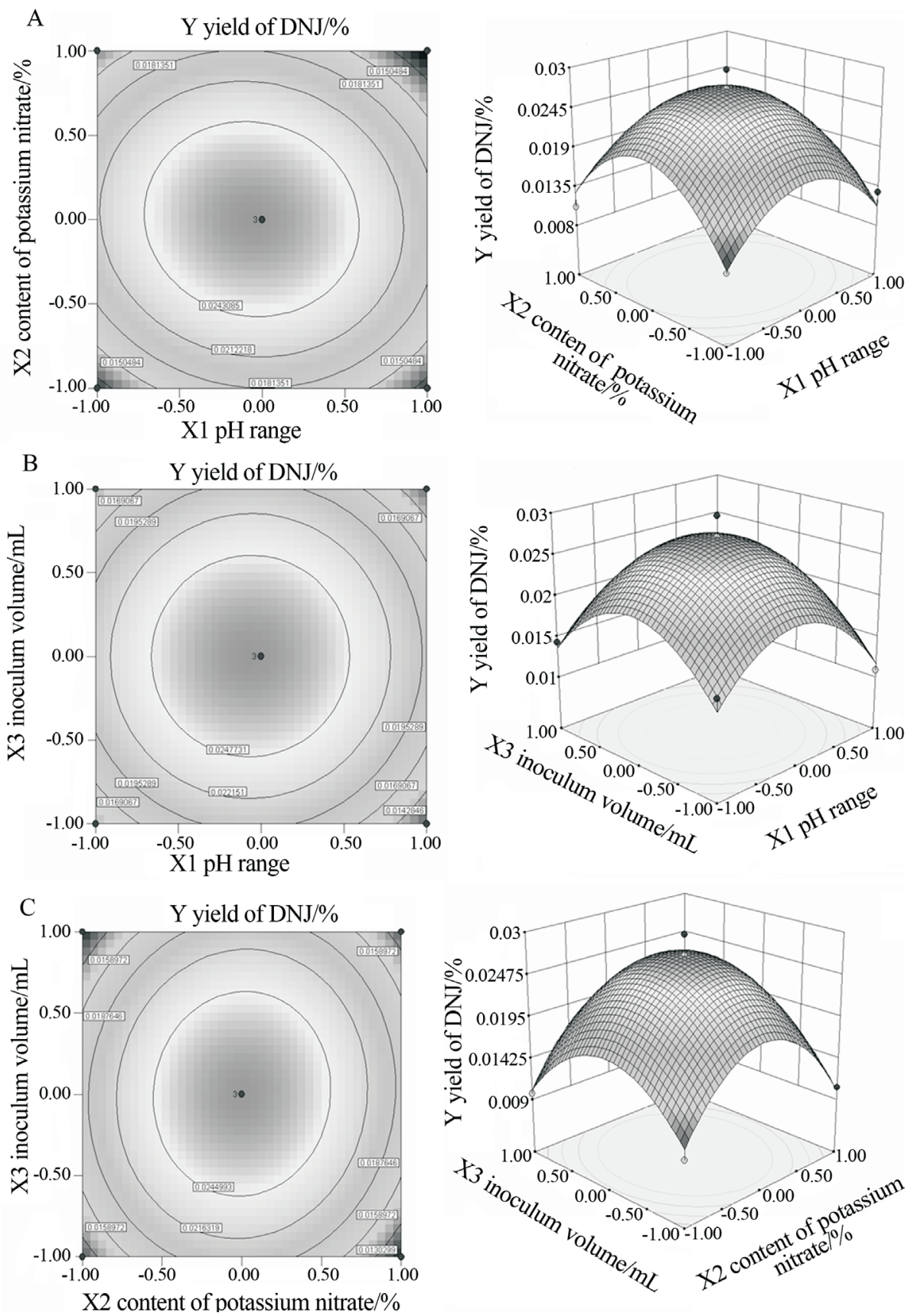

Figure 3 - Contour plots (left) and three-dimensional response (right) of the extraction efficiency (DNJ yield, Y) influenced by $3 \mathrm{a}$ : the range of $\mathrm{pH}$ value $\left(X_{1}\right)$ and content of potassium nitrate $\left(X_{2}\right), 3 \mathrm{~b}$ : the range of $\mathrm{pH}$ value $\left(X_{1}\right)$ and the inoculum volume $\left(X_{3}\right)$, and $3 \mathrm{c}$ : content of potassium nitrate $\left(X_{2}\right)$ and the inoculum volume $\left(X_{3}\right)$.

not destruct the covalent bond within iminosugar in solvent state (Figure 1). In addition, it was reported that okara as nitrogen source can be also detected with DNJ content by some microorganism fermentation. But the separation of DNJ was much complicate (Zhu et al., 2010). As a matter of fact, inorganic nitrogen resource was applied in this study with the advantage of easiness to detect DNJ, and without tedious separation and purification procedures.

It was reported that mulberry resists foreign aggregation by producing high amount of secondary metabolites especially in shoot and young leaves because insects prefer them (Kimura et al., 2007). Considering the present data, there is no doubt that the highest DNJ content can be located in the mulberry leaves taken from the shoot (top part of the branch). As described before, intravenous administration of 1-deoxymannojirimycin (DMJ) showed an interesting distribution that $52 \%$ of it existed in urine, whereas a small amount was detected in liver, heart, kidney and intestinal tact (Faber et al., 1992). The silkworm, Bombyx mori, a mulberry monophagous insect, evolved enzymatic adap- 


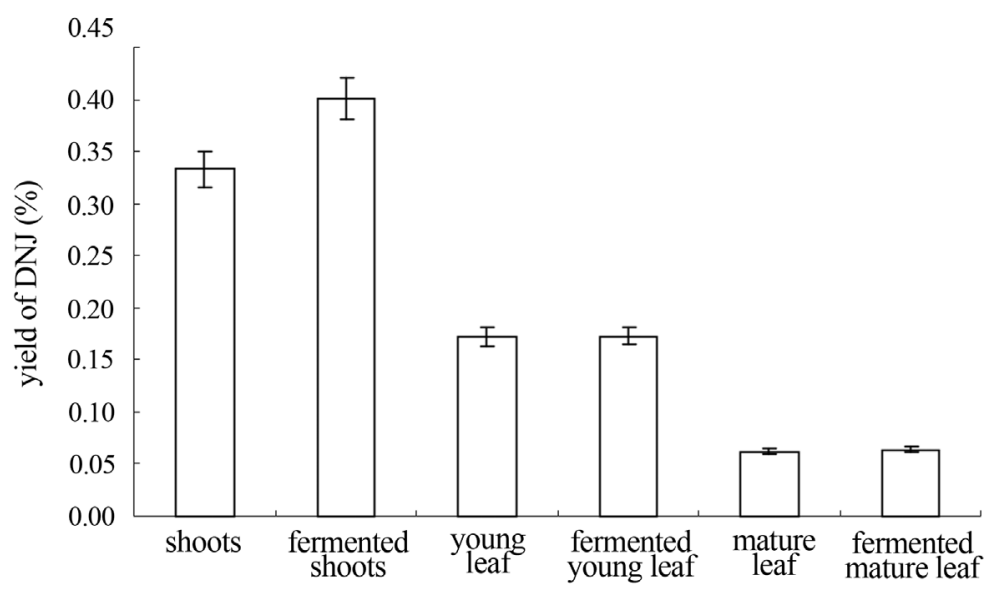

Figure 4 - DNJ production of mulberry leaves fermented by Ganoderma lucidum Value equaled to mean \pm standard derivation in 3 duplicates.

tation to mulberry defense by developing sucrase and trehalase that are insensitive to sugar mimic alkaloids (Hirayama et al., 2007). The same phenomenon of DNJ accumulation in silkworm was also observed. DNJ content in silkworm larvae is 2.7-fold of that in mulberry leaves (Asano et al., 2001), suggesting that it gains some advantage from storing these compounds.

The expression quantity of flavonoid synthetase gene (CHS) in tea leaves decreased along with growth and development of matured plant, resulting in higher content of flavonoid in young leaves in contrast with mature ones (Qiao et al., 2009). Based on this phenomenon, there is likely a hypothesis that shoot or young leaves are preferred by insects. DNJ, as a defense molecule for botany, declined apparently from young leaf to mature leaf. However, DNJ distribution in mulberry leaves also follows this discipline, a difference in concentration from shoot to mature leaves so as not to cause cytotoxicity to itself. DNJ production improved by Ganoderma lucidum fermentation might be involved in activating the amine enzyme involved in of DNJ synthesis induced by mulberry DNJ stimulation. The metabolic intermediates activated by amine enzyme were favorable to increase of DNJ content after fermentation. For mature leaf, metabolic intermediates for DNJ synthesis is insufficient, leading to insignificant improvement in DNJ yields after fermentation. Therefore, it is no wonder that a certain level of metabolites is necessary for the elevation of DNJ by microorganism fermentation.

Ganoderiol F (alcohol fraction) with other components from fungus of Ganoderma lucidum exihibited the strongest cytotoxicity against tumor cell lines, suggesting that there may be trace of iminosugar undetectable in this eukaryote (Gao et al., 2006). In this study, we emphasized on screening out Ganoderma lucidum as a starter culture for mulberry fermentation and optimizing the fermentation conditions for improvement of DNJ production. This is a first report in improving the production of DNJ from mulberry fermented by a strain of Ganoderma lucidum with the optimum conditions. Mixed culture fermentation with the combination of multi-species to improve DNJ production from sericultural biomass in large scale will be further investigated.

\section{Acknowledgments}

This work was supported by the Key Technologies R\&D Program of China grant No. 2011BAD33B04, and the National Public Industry (Agriculture) Program of China grant No. 201403064.

\section{References}

Asano N, Yamashita T, Yasuda, K, Ikeda K, Kizu H, Kameda Y, Kato A, Nash RJ, Lee HS, Ryu KS (2001) Polyhydroxylated alkaloids isolated from mulberry trees (Morus alba L.) and silkworms (Bombyx mori L.). J Agri Food Chem 49:42084213.

Butt MS, Nazir A, Sultan MT, Schroen K (2008) Morus alba L. nature's functional tonic. Trends Food Sci Technol 19:505512.

Chalunton V, Kiyotaka N, Phumon SW, Yasuyo S, Fumiko K, Ohki H, Teruo M (2009) Optimization of 1-deoxynojirimycin extraction production from mulberry leaves by using Response Surface Methodology. Biosci Biotech Biochem 73:2684-2689.

Durantel D, Branza-Nichita N, Carrouee-Durantel S, ButtersTD, Dwek RA, Zitzmann N (2001) Study of the mechanism of antiviral action of iminosugar derivatives against bovine viral diarrhea virus. J Virol 75:8987-8998.

Faber ED, Oosting R, Neefjes JJ, Ploegh HL, Meijer DK (1992) Distribution and elimination of the glycosidases inhibitors 1-deoxynojirimycin and N-methyl-1-deoxynojirimycin in the rat in vivo. Pharm Sci 9:1442-1450.

Fang SH, Hou YC, Chao PD (2005) Pharmacokinetic and pharmacodynamic interactions of morin and cyclosporine. Toxicol Appl Pharmacol 205:65-70.

Gao JJ, Hirakawa A, Min BS, Nakamura N, Hattori M (2006) In vivo antitumor effects of bitter principles from the antlered form of fruiting bodies of Ganoderma lucidum. Chinese. J Nat Med 60:42-48. 
Gui ZZ, Chen J, Chen WH, Zhuang DH (2001) Effect of silkworm powder (SP) lowering blood-glucose levels in mice and its mechanism. Acta Sericol Sinica 27:114-118.

Gui ZZ, Dai JY, Chen JJ, Wang D, Qian FF, Yang L, Zhuang DH (2004) Studies on the edibility and therapeutic effects of the silkworm powder. Acta Sericol Sinica 30:107-110.

Hirayama C, Konno K, Wasano N, Nakamura M (2007) Differential effects of sugar-mimic alkaloids in mulberry latex on sugar metabolism and disaccharidases of Eri and domestic silkworms: enzymatic adaption of Bombyx mori to mulberry defense. Insect Biochem Mol Biol 37:1348-1358.

Jiang YG, Jia JQ, Gui ZZ (2010) Optimizational process of 1-deoxynojirimycin extraction from silkworm larvae by response surface methodology. Genome Appl Biol 29:1-8.

Kameda Y, Asano N, Teranishi M, Matsui K (1980) New cyclitols, degradation of validamycin A by Flavobacterium saccharophilum. J Anti Biotechnol 33:1573-1574.

Kim JW, Kim SU, Lee HS, Kim I, Ahn MY, Ryu KS (2003) Determination of 1-deoxynojirimycin in Morus alba L. leaves by derivatization with 9-fluorenylmethyl chloroformate followed by reversed-phase high-performance liquid chromatography. J Chromatograph A 1002:93-99.

Kimura T, Nakagawa K, Kubota H, Kojima Y, Goto Y, Yamagishi K, Oita S, Oikawa S, Miyazawa T (2007) Food-grade mulberry powder enriched with 1-deoxynojirimycin suppresses the elevation of postprandial blood glucose in humans. J Agri Food Chem 55:5869-5874.

Kojima Y, Kimura T, Nakagawa K, Asai A, Hasumi K, Oikawa S, Miyazawa T (2010) Effects of mulberry leafa extract rich in 1-Deoxynojirimycin on blood lipid profiles in humans. J Clin Biochem Nutrat 47:155-161.

Kojima M, Tachikake N, Kyotani Y, Konno K, Maruo S, Yamamoto M, Ezure Y (1995) Effect of dissolved oxygen an $\mathrm{pH}$ on moranoline (1-deoxyrijimycin) fermentation by Streptomyces lavedulae. J Ferment Bioengin 79:391-394.

Lazar C, Durantel D, Macovei A, Zitzmann N, Zoulim F, Dwek RA, Branza-Nichita N (2007) Treatment of hepatitis B virus-infected cells with $\alpha$-glucosidase inhibitors results in production of virions with altered molecular composition and infectivity. Antiviral Res 76:30-37.

Lee SH, Choi SY, Kim H, Hwang JS, Lee BG, Gao JJ, Kim SY (2002) Mulberroside F isolated from the leaves of Morus alba inhibits melanin biosynthesis. Biol Pharm Bull 25:1045-1048.
Lou DS, Fan T, Wang CY, Yan H, Gui ZZ (2010) Isolation of 1-deoxynojirimycin from silkworm powder and its inhibitory effect on tumor cells. Acta Sericol Sinica 36:109-114.

Niidome T, Takahashi K, Goto Y, Goh SM, Tanaka N, Kamei K, Ichida M, Hara S, Akaike A, Kihara T, Sugimoto H (2007) Mulberry leaf extract prevents amyloid beta-peptide fibril formation and neurotoxicity. Neuroreport 18:813-816.

Qiao XY, Ma CL, Chen L (2009) Plant flavonoid biosynthesis pathway and regulation of its important genes. Nat Prod Res Develop 21:354-360.

Sathish T, Prakasham RS (2010) Enrichment of glutaminase production by Bacillus subtilis RSP-GLU in submerged cultivation based on neural network - genetic algorithm approach. J Chem Technol Biotechnol 85:50-58.

Schmidt DD, Frommer W, Junge B, Muller L, Wingender W, Truscheit E, Schafer D (1977) $\alpha$-Glucosidase inhibitors, new complex oligosaccharides of microbial origin. Naturwissenschaften 64:535-536.

Stein DC, Kopec LK, Yasbin RE, Young FE (1984) Characterization of Bacillus subtilis DSM704 and its production of 1-deoxynojirimycin. Appl Environ Microbiol 48:280-284.

Wei ZJ, Zhou LC, Chen H, Chen GH (2011) Optimization of the fermentation condition for 1-DNJ production by Streptomyces lawendulae applying the RSM. Inter J Food Engin 7:1556-3758.

Yagi M, Kouno T, Aoyagi Y, Murai H (1976) The structure of moraoline, a piperidine alkaloid from Morus species. Nippon Nougei kagaku kaishi 50:571 -572.

Zheng YG, Xue YP, Shen YC (2006) Production of valienamine by a newly isolated strain: Stenotrophomonas maltrophilia. Enzyme Microb Technol 39:1060-1065.

Zhong YL, Morimura S, Kida K (1995) Effect of fermentation temperature on relationship between cell viability and trehalose content of Saccharomyces cerevisiae KF-7 in repeated-batch fermentation. J Ferment Bioengin 80:204-207.

Zhu YP, Yamaki K, Yoshihashi T, Kameyama MO, Li XT, Cheng YQ, Mori Y, Li LT (2010) Purification and Identification of 1-Deoxynojirimycin (DNJ) in Okara Fermented by Bacillus subtilis B2 from Chinese Traditional Food (Meitaoza). J Agri Food Chem 58:4097-4103.

All the content of the journal, except where otherwise noted, is licensed under a Creative Commons License CC BY-NC. 